\title{
Oral mucosal lesions and their association with sociodemographic, behavioral, and health status factors
}

\section{José Nicolau GHENO(a) Marco Antonio Trevizani MARTINS(b) Maria Cristina MUNERATO ${ }^{(c)}$ Fernando Neves HUGO(d) Manoel SANT'ANA FILHO(a) Camila WEISSHEIMER(a) Vinicius Coelho CARRARD(a) Manoela Domingues MARTINS(a)}

(a) Universidade Federal do Rio Grande do Sul - UFRGS, School of Dentistry, Department of Oral Pathology, Porto Alegre, RS, Brazil.

(b) Universidade Federal do Rio Grande do Sul - UFRGS, Hospital de Clínicas de Porto Alegre - HCPA, Stomatology Service, Porto Alegre, RS, Brazil.

(c) Universidade Federal do Rio Grande do Sul - UFRGS, Hospital de Clínicas de Porto Alegre - HCPA, Stomatology Service, Porto Alegre, RS, Brazil.

(d) Universidade Federal do Rio Grande do Sul - UFRGS, School of Dentistry, Center of Community Dental Health Research, Porto Alegre, RS, Brazil.

Declaration of Interests: The authors certify that they have no commercial or associative interest that represents a conflict of interest in connection with the manuscript.

\section{Corresponding Author:}

Manoela Domingues Martins

E-mail:manomartins@gmail.com

DOI: 10.1590/1807-3107BOR-2015.vol29.0093

Submitted: Sep 24, 2014

Accepted for publication: Mar 30, 2015

Last revision: Jun 18, 2015

\begin{abstract}
The aim of this study was to evaluate the frequency of oral mucosal lesions and their associations with sociodemographic, health, and behavioral factors in a southern Brazilian population. Information was collected from participants $(\mathrm{n}=801)$ using a structured questionnaire during an oral cancer screening campaign held at an agribusiness show in southern Brazil in 2009. Data were described using frequency distributions or means and standard deviations. Associations between independent variables and outcomes were assessed using the Chi-squared test. A total of 465 lesions were detected (actinic cheilitis: $\mathrm{n}=204,25.5 \%$; candidiasis: $\mathrm{n}=50,6.2 \%$; fibrous inflammatory hyperplasia: $\mathrm{n}=42,5.2 \%$; ulceration, $\mathrm{n}=33,4.1 \%$; hemangioma: $\mathrm{n}=14$, 1.7\%; leukoplakia: $\mathrm{n}=11,1.4 \%$ ). Candidiasis, actinic cheilitis, and fibrous inflammatory hyperplasia were associated significantly with literacy. Actinic cheilitis was also associated significantly with sun exposure and hat use, and leukoplakia was associated with smoking. The high frequency of oral mucosal lesions observed highlights the importance of education about risk factors. Additionally, training of health professionals, mainly those from public health services, in the use of preventive and community education strategies is needed.
\end{abstract}

Keywords: Mouth Neoplasms; Ulcer; Candidiasis; Health Status.

\section{Introduction}

The etiologies of oral mucosal lesions include infection, local trauma, and metabolic, immunologic, and neoplastic diseases. ${ }^{1}$ Surveys have demonstrated that the prevalence of these lesions varies across the world in association with factors such as skin color, sex, exposure to risk factors for oral cancer, general health status of sample populations, and diagnostic criteria. ${ }^{2}$ Epidemiologic studies of oral mucosal lesions are scarce compared with investigations of caries and periodontal disease. ${ }^{3}$ Several such studies have been carried out in samples of people with specific diseases, such as oral cancer ${ }^{1,2,3,4}$ and diabetes, ${ }^{5}$ as well as those with particular chronic conditions and specific age groups. ${ }^{6,7}$ Apart from population characteristics, geographic differences in the prevalence of these lesions may also be explained by the use of various experimental designs for their examination. However, as a rule, these studies have shown that the occurrence of oral lesions tends to increase with age, and is higher in male subjects, smokers, and alcoholics. ${ }^{8}$ 
Investigation of the epidemiology and occurrence of oral lesions has become an important tool in understanding the prevalence, extent, and degree of oral diseases in the general population. $1,2,3,4,5,8,7,8,9,10$ Although the World Health Organization recommends oral cancer screening, few studies have been published on this subject, in contrast to other oral diseases. Accurate estimates of the occurrence of these lesions and more in-depth comprehension of their relationship to social determinants are essential for prevention and health promotion..$^{10}$ The aim of the present study was to determine the frequency of oral mucosal lesions and evaluate associations with sociodemographic, health, and behavioral factors in a southern Brazilian population.

\section{Methodology}

\section{Experimental design and sample}

The Committee for Ethics in Research, Universidade Federal do Rio Grande do Sul - UFRGS, Brazil, approved this cross-sectional study (protocol no. 18.980). The sample population comprised participants in an oral cancer awareness screening campaign held in 2009 during an agribusiness show in the city of Esteio, RS, Brazil.

A structured questionnaire was used to collect data pertaining to participants' sociodemographic characteristics (sex, age, self-reported skin color, monthly income, place of residence, and literacy). Self-reported skin color was dichotomized as white or non-white. Monthly income, in reais ( $R \$$, the currency of Brazil), was categorized as $\leq \mathrm{R} \$ 500$, $\mathrm{R} \$ 501-1000, \mathrm{R} \$ 1001-1500,>\mathrm{R} \$ 1500$, or not indicated. Literacy was classified according to educational level (elementary, high school [including dropouts], or university [including dropouts]).

Data on alcohol consumption (no, yes, former drinker), tobacco smoking (no, yes, former smoker; number of cigarettes/day), mate tea consumption (no, yes; liters/day), coffee consumption (no, yes; cups/day), sun exposure (no, yes; hours/day), hat use (no, yes), and sunscreen use (no, yes) were also recorded. Self-reported health status was investigated using dichotomized response options (no, yes). The most prevalent systemic diseases were regarded as hypertension, diabetes, hepatitis, and high cholesterol. Daily use of medication (no, yes) was determined during the interview, and the most common drugs were antihypertensives, diuretics, hypoglycemics, antibiotics, analgesics, non-steroidal anti-inflammatory drugs (NSAIDs), and contraceptives.

Examinations of the oral cavity were supervised by an experienced stomatologist. The location, size, color, base characteristics, fundamental lesion, and consistency of lesions were recorded, along with respective diagnostic hypotheses. In cases of suspected oral lesion diagnosis, participants were referred for treatment at the School of Dentistry, UFRGS, or to a National Health Service unit (Sistema Único de Saúde - SUS).

\section{Statistical analysis}

The data collected from each participant were used to construct a data set. Categorical variables were described in terms of absolute and relative frequencies, and continuous variables were described as means and standard deviations. Associations of independent variables with outcomes were assessed using the Chi-squared or Fisher's exact test, as applicable (SPSS 13; SPSS Inc., Chicago, USA). A significance level of $5 \%$ was used for all tests.

\section{Results}

\section{Sociodemographic and behavioral characteristics}

The mean age of the 801 participants was 51.33 (range, 11-88) years. All other sociodemographic data are shown in Table 1.

Table 2 shows the behavioral characteristics of the participants. Drinkers were more likely to be smokers $(p=0.01)$.

\section{Health status}

Concerning the occurrence and distribution of systemic diseases, 197 (24.6\%) participants were hypertensive, $120(15 \%)$ had hypercholesterolemia, $45(5.6 \%)$ had diabetes, and $36(4.5 \%)$ had hepatitis. A total of $178(22.2 \%)$ participants reported antihypertensive drug use. Fifty-four (6.7\%) participants used diuretics, 31 (3.9\%) used hypoglycemic drugs, 26 (3.2\%) used contraceptives, 24 (3\%) used analgesics, $13(1.6 \%)$ used NSAIDs, and $3(0.4 \%)$ used antibiotics. Conversely, 566 (70.7\%) participants stated that they used no medication. 
Table 1. Distribution of individuals assessed according to sociodemographic variables.

\begin{tabular}{lcc}
\hline & $\mathrm{n}$ & $(\%)$ \\
\hline Gender & & \\
Male & 439 & 54.8 \\
$\quad$ Female & 362 & 45.2 \\
Skin color & & \\
$\quad$ White & 718 & 89.6 \\
$\quad$ Non-white & 36 & 4.5 \\
$\quad$ Not informed & 47 & 5.9 \\
Literacy & & \\
Elementary & 321 & 40.1 \\
$\quad$ High school (including drop-outs) & 262 & 32.7 \\
College (including drop-outs) & 203 & 25.4 \\
Not informed & 15 & 1.8 \\
Income (R $\$$ ) & & \\
$\quad \leq 500$ & 135 & 16.9 \\
$501-1,000$ & 233 & 29.1 \\
1,001 - 1,500 & 120 & 15 \\
$>1,500$ & 295 & 36.8 \\
Not informed & 18 & 2.2 \\
Total & 801 & 100 \\
\hline
\end{tabular}

\section{Oral mucosal lesions}

A total of 465 lesions were diagnosed in 376 (46.9\%) participants. Of these, $301(80.05 \%)$ presented one lesion, 63 (16.75\%) had two, 10 (2.65\%) had three, and $2(0.55 \%)$ had four lesions. The most common lesions were actinic cheilitis $(\mathrm{n}=204,43.9 \%)$, candidiasis $(\mathrm{n}=50,10.7 \%)$, fibrous inflammatory hyperplasia

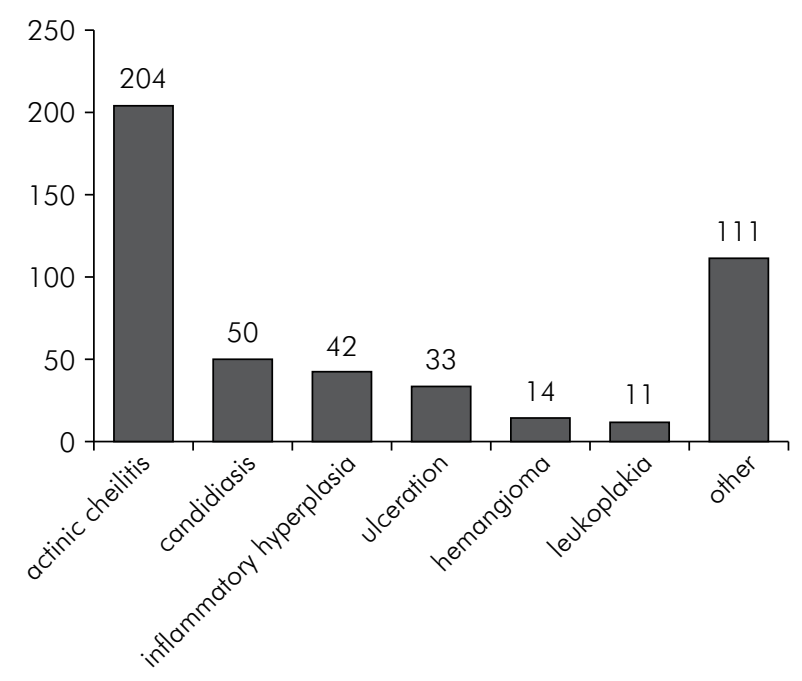

Figure. Prevalence of oral mucosa lesions in individuals examined.
Table 2. Distribution of individuals assessed according to behavioral variables.

\begin{tabular}{|c|c|c|}
\hline & $\mathrm{n}$ & $\%$ \\
\hline \multicolumn{3}{|l|}{ Smoking } \\
\hline Smoker & 70 & 8.7 \\
\hline Non-smoker & 549 & 68.6 \\
\hline Former smoker & 182 & 22.7 \\
\hline \multicolumn{3}{|l|}{ Alcohol } \\
\hline Yes & 407 & 50.8 \\
\hline No & 394 & 49.2 \\
\hline \multicolumn{3}{|c|}{ Smoking and alcohol consumption } \\
\hline Non-smoker, non-drinker & 371 & 46.31 \\
\hline Only drinker & 360 & 44.94 \\
\hline Smoker and drinker & 47 & 5.86 \\
\hline Only smoker & 23 & 2.89 \\
\hline \multicolumn{3}{|l|}{ Sun exposure } \\
\hline Yes & 528 & 65.9 \\
\hline No & 273 & 34.1 \\
\hline Hours a day - mean & 4.77 & \\
\hline \multicolumn{3}{|l|}{ Hat use } \\
\hline Yes & 349 & 43.6 \\
\hline No & 452 & 56.4 \\
\hline \multicolumn{3}{|l|}{ Sunblock use } \\
\hline Yes & 244 & 30.5 \\
\hline No & 557 & 69.5 \\
\hline \multicolumn{3}{|l|}{ Coffee consumption } \\
\hline Yes & 523 & 65.3 \\
\hline No & 278 & 34.7 \\
\hline Cups a day - mean & 2.32 & \\
\hline \multicolumn{3}{|l|}{ Mate tea consumption } \\
\hline Yes & 512 & 63.9 \\
\hline No & 289 & 36.1 \\
\hline Liters a day - mean & 1.12 & \\
\hline Total & 801 & 100 \\
\hline
\end{tabular}

( $\mathrm{n}=42,9 \%)$, ulcerations $(\mathrm{n}=33,7 \%)$, hemangioma $(\mathrm{n}=14,3 \%)$, and leukoplakia $(\mathrm{n}=11,2.4 \%)$. Less frequently occurring lesions were observed in 111 (24\%) cases (Figure).

The presence of actinic cheilitis was associated significantly with fibrous inflammatory hyperplasia and low literacy. The prevalence of actinic cheilitis was associated with candidiasis (Table 3). Skin color and sex were also associated significantly with the prevalence of actinic cheilitis, with white people $(\mathrm{p}=0.01$; odds ratio $[\mathrm{OR}]=4.07,95 \%$ confidence interval $[\mathrm{CI}]=1.23-13.43)$ and male subjects $(\mathrm{p}<0.05$, 
Table 3. Association between literacy and prevalence of actinic cheilitis, candidiasis and inflammatory hyperplasia.

\begin{tabular}{lcccccc}
\hline \multirow{2}{*}{ Literacy } & \multicolumn{2}{c}{ Actinic cheilitis } & \multicolumn{2}{c}{ Candidiasis } & \multicolumn{2}{c}{ Inflammatory Hyperplasia } \\
\cline { 2 - 6 } & No & Yes & No & Yes & No & Yes \\
\hline Elementary & $214(66.7 \%)$ & $107(33.3 \%)$ & $288(89.7 \%)$ & $33(10.3 \%)$ & $296(92.2 \%)$ & $25(7.8 \%)$ \\
High school (including drop-outs) & $204(77.9 \%)$ & $58(22.1 \%)$ & $252(96.2 \%)$ & $10(3.8 \%)$ & $257(98.1 \%)$ & $5(1.9 \%)$ \\
College (including drop-outs) & $170(83.7 \%)$ & $33(16.3 \%)$ & $198(97.5 \%)$ & $5(2.5 \%)$ & $192(94.6 \%)$ & $11(5.4 \%)$ \\
\hline
\end{tabular}

$\mathrm{OR}=3.73,95 \% \mathrm{CI}=2.6-5.37)$ more likely to present these lesions. The frequency of actinic cheilitis was associated significantly with greater sun exposure $(p=0.05)$; accordingly, it was negatively associated with hat use. Hat use was correlated significantly with the extent of sun exposure (OR $=2.95,95 \%$ $\mathrm{CI}=2.12-4.1)$.

The prevalence of candidiasis was associated with low income ( $\mathrm{p}=0.02, \mathrm{OR}=2.82,95 \% \mathrm{CI}=1.14-6.97)$. Individuals who reported oral hypoglycemic drug use $(\mathrm{p}=0.03, \mathrm{OR}=3.098,95 \% \mathrm{CI}=1.13-8.45)$ also had a higher risk of candidiasis development. No significant association was observed between oral mucosal lesions and the use of antihypertensives, diuretics, contraceptives, analgesics, NSAIDs, or antibiotics. The prevalence of leukoplakia was associated positively with smoking $(\mathrm{p}=0.011, \mathrm{OR}=6.26,95 \% \mathrm{CI}=1.78-21.96)$.

\section{Discussion}

This study evaluated the frequency of oral lesions and associated factors using data collected during an oral cancer screening campaign in southern Brazil. In contrast to the majority of studies on this issue, which have assessed urban populations, the present study sample was composed predominantly of individuals from a rural area. The results reinforced previous findings that some sociodemographic indicators influence oral health, ${ }^{11}$ notably in relation to oral mucosal lesions.

A large proportion (46.9\%) of the population presented oral mucosal lesions, similar to percentages reported by Espinoza et al. ${ }^{3}$ and Garcia-Pola et al. ${ }^{8}$ However, participants in the present study comprised a convenience sample that was not representative of the southern Brazilian population. Hence, further direct comparisons by lesion type are unwarranted.

In previous studies, factors such as age, ${ }^{4}$ sex, ${ }^{4,5,6,7,8,9,10}$ tobacco smoking, ${ }^{1}$ alcohol consumption, ${ }^{8,9,10}$ socioeconomic status, ${ }_{10}^{10}$ oral prosthesis use ${ }_{10}^{10}$ and health status ${ }^{8}$ have been associated with the occurrence of oral mucosal lesions. Our data demonstrated similar associations for actinic cheilitis, candidiasis, inflammatory fibrous hyperplasia, and leukoplakia.

The present sample comprised mainly farm workers and others who worked outdoors. As expected and in agreement with previous studies, actinic cheilitis was associated with male sex, white skin color, greater sun exposure, and non-use of photoprotection. In agreement with Sousa Lucena et al., ${ }^{12}$ we also found that oral lesions were more likely in individuals with lower literacy. This result may be explained by the characteristics of people in this group, who give low priority to self-care and have harmful health habits, in addition to lacking awareness about oral diseases. ${ }^{13}$

Candidiasis was correlated positively with the use of oral hypoglycemic drugs to control diabetes mellitus. Vasconcelos et al. ${ }^{14}$ reported a significantly greater frequency of candidiasis in diabetic than in non-diabetic patients. The mechanism by which diabetes acts as a risk factor for oral candidiasis has not been fully clarified. However, high glucose levels, ${ }^{15}$ low salivary flow, ${ }^{16}$ and low saliva $\mathrm{pH}$, characteristic of diabetic patients, are known to favor fungal growth. Thus, specific training for health professionals in oral care and the risk of fungal diseases could play an important role in health promotion in this group of patients.

The majority of patients with candidiasis used removable prostheses, associated with an 8.5-times increase in the likelihood of developing this condition. ${ }^{17}$ Long-term prosthesis use affects the occurrence of several lesion types, including denture stomatitis, a clinical subtype of candidiasis. ${ }^{18}$ Most edentulous people have lower income and literacy levels, less access to services, and poor self-rated oral health ${ }^{19}$ and hygiene. ${ }^{20}$ These factors may influence candida colonization. ${ }^{21}$

The frequency of fibrous inflammatory hyperplasia was also related to removable prosthesis use, as shown in other studies, ${ }^{10,19}$ particularly those examining long- 
term use. ${ }^{19}$ Modification of the alveolar ridge occurs over time in these patients, ${ }^{22}$ requiring replacement of the prosthesis as it becomes ill-fitting. However, patients from socioeconomically disadvantaged groups have been found to frequently choose lessexpensive treatments ${ }^{23,24}$ and probably do not have the resources required for prosthesis replacement. ${ }^{25}$ Thus, individuals with lower incomes are assumed to use the same removable prostheses for longer periods of time, favoring candidiasis occurrence.

Even with recent advances, access to health services remains limited in Brazil ${ }^{26}$ particularly in rural areas. ${ }^{27}$ Clearly, municipalities with better infrastructure, including transportation, community integration, and health services, provide more access to health services. ${ }^{28}$ These aspects apparently generate inequalities that modify the oral health profiles of rural populations. In addition, general medical and dental practitioners need better training in the diagnosis of oral conditions. ${ }^{29}$ The lack of skills in oral mucosal lesion detection and oral diagnostic processes probably contributes to the underestimation of lesion prevalence. The data from this study highlight the importance of education in oral health promotion for

\section{References}

1. Mehrotra R, Thomas S, Nair P, Pandya S, Singh M, Nigam NS, Shukla P. Prevalence of oral soft tissue lesions in Vidisha. BMC Res Notes. 2010 Jan;3:23. doi: 10.1186/1756-0500-3-23.

2. Bánóczy J, Rigó $\mathrm{O}$, Albrecht M. Prevalence study of tongue lesions in a Hungarian population. Community Dent Oral Epidemiol. 1993 Aug;21(4):224-6.

3. Espinoza I, Rojas R, Aranda W, Gamonal J. Prevalence of oral mucosal lesions in elderly people in Santiago, Chile. J Oral Pathol Med. 2003 Nov;32(10):571-5.

4. Marocchio LS, Lima J, Sperandio FF, Corrêa L, Souza SOM. Oral squamous cell carcinoma: an analysis of 1,564 cases showing advances in early detection. J Oral Sci. 2010 Jun;52(2):267-73.

5. Saini R, Al-Maweri AA, Saini D, Ismail NM, Ismail AR. Oral mucosal lesions in non oral habit diabetic patients and association of diabetes mellitus with oral precancerous lesions. Diabetes Res Clin Pract. 2010 Sep;89(3):320-6.

6. Güleç AT, Haberal M. Lip and oral mucosal lesions in 100 renal transplant recipients. J Am Acad Dermatol. 2009 Jan;62(1):96-101. health professionals and the general population. ${ }^{30}$ These activities should be included in oral cancer screening campaigns to improve their effectiveness.

\section{Conclusion}

The high frequency of oral mucosal lesions observed in this study highlights the importance of orientation about risk factors. Additionally, training of health professionals, mainly those in public health services, in the use of preventive and community education strategies is needed. Different types of health professional can potentially contribute to routine inspections of the oral mucosa, improving the early diagnosis of lesions, especially those that may evolve into cancer. Furthermore, measures to reduce social and economic inequalities may improve oral health indicators.

\section{Acknowledgments}

Fernando Neves Hugo, Manoel Sant'Ana Filho and Manoela Domingues Martins are research fellows of the Brazilian National Council of Scientific and Technological Development (Conselho Nacional de Desenvolvimento Científico e Tecnológico - CNPq).

7. Majorana A, Bardellini E, Flocchini P, Amadori F, Conti G, Campus G. Oral mucosal lesions in children from 0 to 12 years old: ten years' experience. Oral Surg Oral Med Oral Pathol Oral Radiol Endod. 2010 Jul;110(1):e13-e18.

8. Garcia-Pola Vallejo MJ, Martinez Diaz-Canel AI, Garcia Martin JM, Gonzalez Garcia M. Risk factors for oral soft tissue lesions in an adult Spanish population. Community Dent Oral Epidemiol. 2002 Aug;30(4):277-85.

9. Kulak-Ozkan Y, Ozkan Y, Kazazoglu E, Arıkan A. Dental caries prevalence, tooth brushing and periodontal status in 150 young people in Istanbul: a pilot study. Int Dent J. 2001 Dec;51(6):451-6.

10. Carrard VC, Haas AN, Rados PV, Sant'ana Filho M, Oppermann RV, Albandar JM, Susin C. Prevalence and risk indicators of oral mucosal lesions in an urban population from South Brazil. Oral Dis. 2011 Mar;17(2):171-9.

11. Paulander J, Axelsson P, Lindhe J. Association between level of education and oral health status in 35-, 50-, 65- and 75-year-olds. J Clin Periodontol. 2003 Aug;30(8):697-704.

12. Lucena EES, Costa DC, Silveira EJ, Lima KC. Prevalence and factors associated to actinic cheilitis in beach workers. Oral Dis. 2012 Sep;18(6):575-9. 
13. Afonso-Souza G, Nadanovsky P, Chor D, Faerstein E, Werneck GL, Lopes CS. Association between routine visits for dental checkups and self-perceived oral health in an adult population in Rio de Janeiro: the Pró-Saúde Study. Community Dent Oral Epidemiol. 2007 Oct;35(5):393-400.

14. Vasconcelos BCE, Novaes M, Sandrini FAL, Maranhão Filho AWA, Coimbra LS. Prevalence of oral mucosa lesions in diabetic patients: a preliminar study. Braz J Otorhinolaryngol. 2008 May-Jun;74(3):423-8.

15. Soysa NS, Samaranayake LP, Ellepola NA. Diabetes mellitus as a contributory factor in oral candidosis. Diabet Med. 1999 May;23(5):455-9.

16. Kadir T, Pisiriciler R, Akyuz S, Yarat A, Emekli N, Ipbuker A. Mycological and cytological examination of oral candidal carriage in diabetic patients and non-diabetic control subjects: thorough analysis of local aetiologic and systemic factors. J Oral Rehabil. 2002 May;29(5):452-7.

17. Santos PJB, Bessa CFN, Aguiar MCF, Carmo MAV. Crosssectional study of oral mucosal conditions among central Amazonian Indian community, Brazil. J Oral Pathol Med. 2004 Jan;33(1):7-12.

18. Mandali G, Sener ID, Turker SB, Ülgen H. Factors affecting the distribution and prevalence of oral mucosal lesions in complete denture wearers. Gerodontology. 2011 Jun;28(2):97-103.

19. Hugo FN, Hilgert JB, Sousa ML, Silva DD, Pucca GA. Correlates of partial tooth loss and edentulism in the Brazilian elderly. Community Dent Oral Epidemiol. 2007 Jun;35(3):224-32.

20. Davidson PL, Rams TE, Andersen RM. Socio-behavioral determinants of oral hygiene practices among USA ethnic and age groups. Adv Dent Res. 1997 May;11(2):245-53.
21. Grimoud AM, Lodter JP, Marty N, Andrieu S, Bocquet $\mathrm{H}$, Linas MD, et al. Improved oral hygiene and Candida species colonization level in geriatric patients. Oral Dis. 2005 May;11(3):163-9.

22. Ulm C, Solar P, Blahout R, Matejka M, Gruber H. Reduction of the compact and cancellous bone substances of the edentulous mandible caused by resorption. Oral Surg Oral Med Oral Pathol. 1992 Aug;74(2):131-6.

23. Susin C, Oppermann RV, Haugejoden O, Albadar JM. Tooth loss and associated risk indicators in an adult urban population from south Brazil. Acta Odontol Scand. 2005 Apr;63(2):85-93.

24. Padilha DM, Hilgert JB, Hugo FN, Bos AJ, Ferrucci L. Number of teeth and mortality risk in the Baltimore Longitudinal Study of Aging. J Gerontol A Biol Sci Med Sci. 2008 Jul;63(7):739-44.

25. Meskin LH, Mason LD. Problems in oral health care financing for the elderly. Clin Geriatr Med. 1992 Aug;8(3):685-92.

26. Paim J, Travasos C, Almeida C, Bahia L, Machinko J. The Brazilian health system: history, advances, and challenges. Lancet. 2011 May;377(9779):1778-97.

27. Travassos C, Viacava F. Access to and use of health services by rural elderly, Brazil, 1998 and 2003. Cad Saude Publica. 2007 Oct;23(10):2490-502.

28. Macintyre S, Maciver S, Sooman A. Area, class and health: should we be focusing on places or people?. J Soc Policy. 1993 Apr;22(2):213-34.

29. Sardella A, Demarosi F, Lodi G, Canegallo L, Rimondini L, Carrassi A. Accuracy of referrals to a specialist oral medicine unit by general medical and dental practitioners and the educational implications. J Dent Educ. 2007 Apr;71(4):487-91.

30. Marmot M, Bell R. Social determinants and dental health. Adv Dent Res. 2011 May;23(2):201-6. 